\title{
Relationship between Cirrus Particle Size and Cloud Top Temperature
}

\author{
Qingyuan Han, Joyce Chou, and Ronald M. Welch \\ Institute of Atmospheric Sciences \\ South Dakota School of Mines and Technology \\ 501 E. Saint Joseph Street \\ Rapid City, SD 57701-3995 \\ Phone: (605) 394-2291; Fax (605) 394-6061 \\ email: han@cloud.ias.sdsmt.edu
}

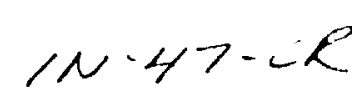

parameterize the ice crystal size as Heymsfield and Platt [6]

Abstract - The relationship between cirrus particle size and cloud top temperature is surveyed on a near-global scale. The cirrus particle size is retrieved assuming ice crystals are hexagonal columns and the cloud top temperature and the radiaces in channel 1 and 3 of AVHRR used to retrieve ice particle sizes are from ISCCP product. The results show that for thick clouds over North America, the relation between cirnus particle size and cloud top temperature is consistent with a summary of this relationship based on aircraft measurement over that region for thick clouds. However, this relationship is not universal for other regions especially for tropical zone, which has been found by other in situ measurements.

\section{INTRODUCTION}

Cloud microphysical parameterizations have attracted a great deal of attention in recent years due to their effect on cloud radiative properties [1] and cloud-related hydrological processes in large-scale models [2] The parameterization of cirrus particle size has been demonstrated as an indispensable component in the climate feedback analysis [3]. In parameterization schemes, relationships between cloud temperatures/optical thickness and cirrus ice crystal sizes are of critical importance because the microphysics of cirrus clouds modifies the relationship between cloud optical depth and cloud ice/liquid water path. Climate models not accounting for this relationship cannot correctly predict the temperature dependence of infrared emittance of cirrus clouds [4] and thus arrive at wrong conclusions about climate change. Many efforts have been made to investigate the cloud temperature-cirnus crystal size relationship and controversial conclusions have been reached. For example, twenty flights of aircraft measurements over North America during winter times $[5,6]$ show that the cloud-particle mode radius increases with temperature. Similar results were found by in situ measurement during CEPEX at tropics [7] and by surface lidar observations [8]. However, investigations using radar measurements [9], Doppler radar

and IR radiometry [10], and millimeter-wave radar [11] found a negative correlation between ice crystal size and temperature and conclude that temperature cannot be used to suggested. While these data supply valuable information about this relationship, they are all regional measurements during a short time period for mostly thick cirrus clouds.

This study investigates this relationship based on the cirnus particle size data retrieved from ISCCP CX data. We found that for thick clouds ( $\tau \geq 10$ ), similar to those found by aircraft measurements, most of the regions over the globe show positive relationships between cloud temperature and cirrus ice crystal sizes. However, if relatively thin clouds are included $((\tau \geq 3)$, this correlation becomes negative for tropical areas but remains mostly positive for midlatitudes.

\section{RETRIEVAL OF ICE CRYSTAL PARTICLE SIZE}

The detailed methodology of retrieving ice crystal size is presented in another paper [12]. In that paper, the method for retrieving cimus particle size information on a nearglobal scale $\left(50^{\circ} \mathrm{S}\right.$ to $\left.50^{\circ} \mathrm{N}\right)$ using currently available satellite data from ISCCP is described. To retrieve cirrus particle size, we use a radiative transfer model that includes all major absorbing gases and cloud scattering / absorption to compute synthetic radiances as a function of satellite viewing geometry. Ice clouds are determined by cloud top temperatue $T_{c} \leq 240 \mathrm{~K}$. Shapes and orientations of ice crystals are assumed to be hexagonal columns and plates randomly oriented in the atmosphere. Although ice crystals may have complicated shapes such as bullets, rosettes, aggregates, irregular and quasi-spherical particles and show preferred orientations, it is difficult to determine which shape and/or orientation is dominant in a specific clouds by current remote sensing instruments. On one hand, we realize the possible effect of non-hexagonal particles and preferred orientations. On the other hand, we also notice that the difference of phase functions between hexagon and other irregular shapes is much smaller than that of nonspherical and spherical particles [13]. Therefore, we adopt the phase functions for hexagonal columns in the retrieval and estimate the possible effect of non-hexagonal and preferred orientation by comparing the retrieved particle sizes with in situ measurements. Ray tracing techniques are used to calculate phase functions for different size distributions. Five different size distributions from

Acknowledgement. We wish to thank Dr. Ou and Takano for supplying phase functions used in this study. This research was supported by NASA Grant Nos. NAGW-3922, NAGW-3788; was partially funded by DOE through the NIGEC Great Plains Regional Center at the University of Nebraska-Lincoln (DOE Cooperative Agreement No. DEFC03-90ER61010). Financial support does not constitute an endorsement by DOE of the views expressed in this paper. This research was also supported by the NASA Climate Program managed by Dr. Bob Curran. 


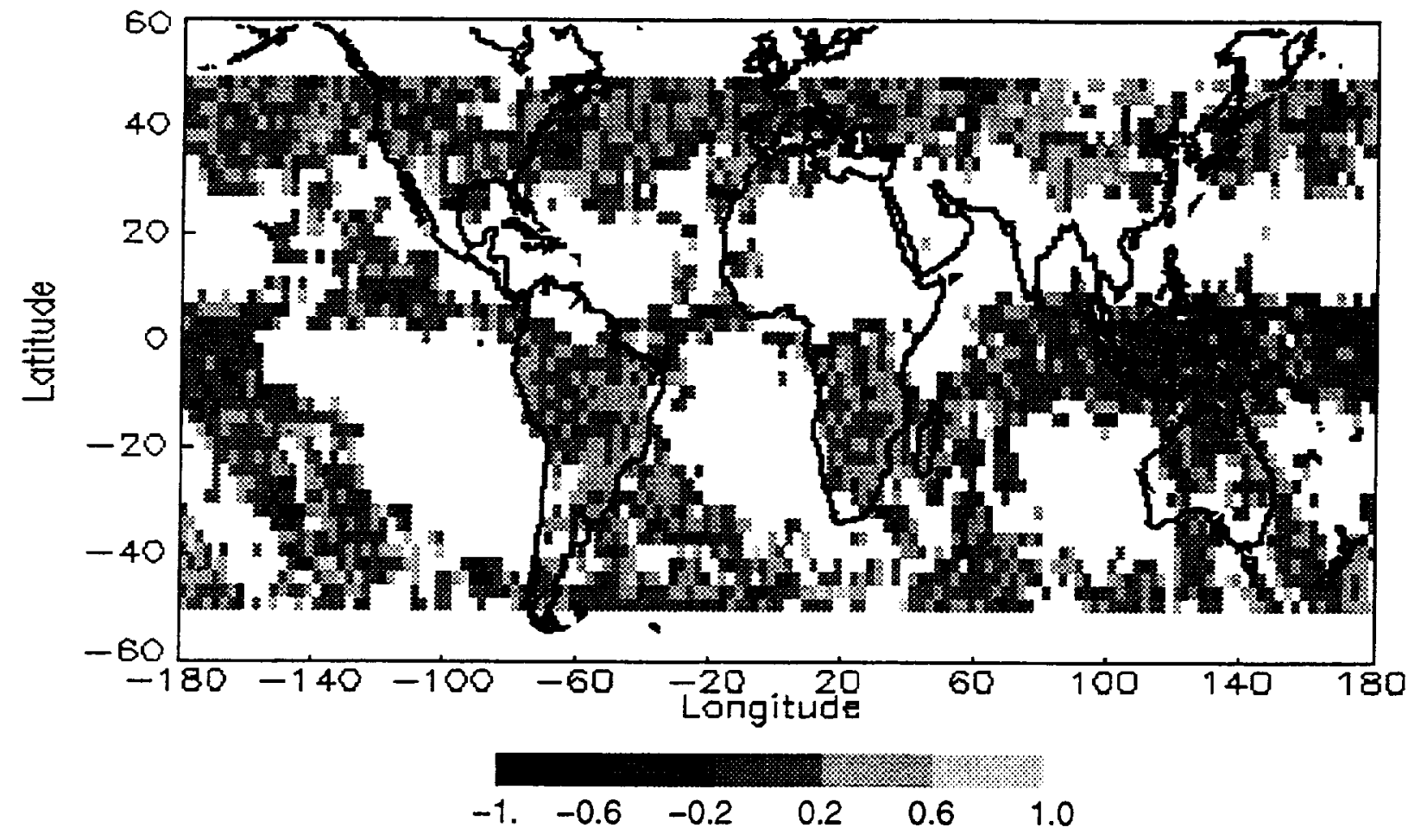

Fig. 1 Correlation (De, Tc) for Ice Cloud ( $\tau>=10 ; 8701$ NOAA-9)

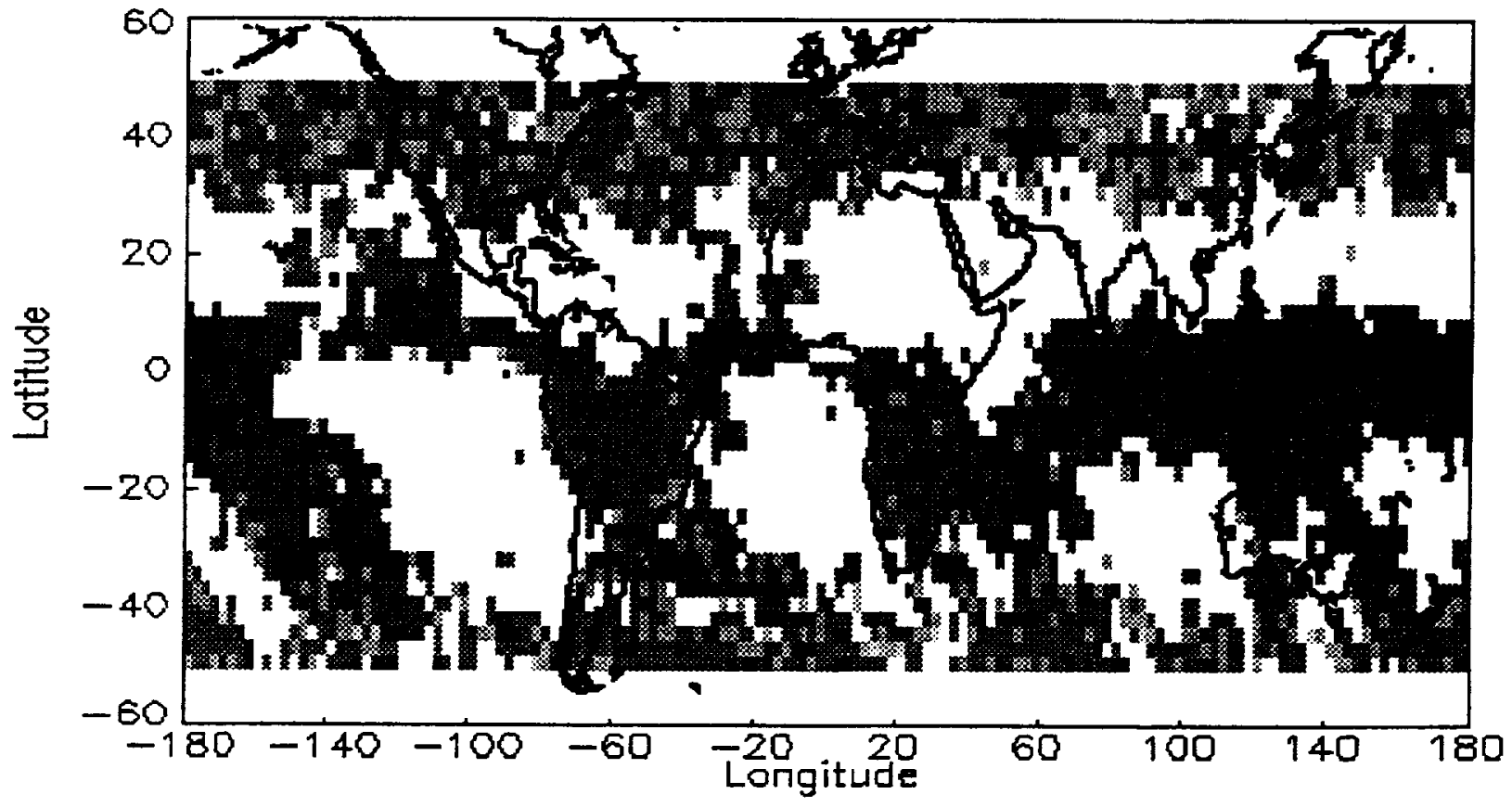

$\begin{array}{llllll}-1 . & -0.6 & -0.2 & 0.2 & 0.6 & 1.0\end{array}$

Fig. 2 Correlation (De, TC) for Ice Cloud ( $\tau>=3 ; 8701$ NOAA-9) 
cirrus $\left(D_{e}=47.6 \mu \mathrm{m}\right),-40^{\circ} \mathrm{C}$ cirrus $\left(D_{e}=64.1 \mu \mathrm{m}\right)$, Nov. 1 cirrus $\left(D_{e}=75.1 \mu \mathrm{m}\right)$ and Cirrus uncinus $\left(D_{e}=123.6 \mu \mathrm{m}\right)$. Phase functions of these five size distributions for channels 1 and 3 of AVHRR are applied in the model for calculations of multiple scattering. The model results have been validated against clear sky observations and are consistent with the observed radiance range under cloudy conditions.

The results of this near-global survey show that the peak frequency of cirrus crystal effective diameter $D_{e}$ for hexagons is about $60 \mu \mathrm{m}$, the mean value corresponding to a $30 \mu \mathrm{m}$ radius for an equivalent sphere. The survey also reveals that about $15 \%$ of the small crystal sizes are less than $23 \mu \mathrm{m}$ in effective diameter. The geographical distribution of small crystal sizes is consistent with the results of Prabhakara et al. [14]. There are no significant differences between particle sizes of continental and maritime cirnus.

\section{RELATION BETWEEN ICE CRYSTAL SIZE AND TEMPERATURE}

Figure 1 shows the distribution of correlation coefficients between ice cloud crystal size and cloud top temperature for thick clouds $(\tau \geq 10)$. Ice clouds over most of the regions show positive relation between ice crystal size and cloud top temperature, consistent with the results of Heymsfield and Platt (1984). However, this relation changes when thin clouds are included into the statistics. Figure 2 shows that for ice clouds with ( $\tau \geq 3$, most ice clouds over tropical and sub-tropical regions show negative relation between ice particle sizes and cloud top temperature. The possible explanation includes different cirrus systems over tropics and midlatitudes. The strong convective motion in tropics brought large ice crystal particles up to very high and cold regions and spread out to form vast and relatively thin anvils. Further information about the underlying mechanism and possible explanations are under investigation.

\section{REFERENCES}

[1] Stephens, G. L., 1984: The parameterization of radiation for numerical weather prediction and climate models. Mon. Wea. Rev. 112, 826-867.

[2] Fowler, L. D., and D. A. Randall, 1996: Liquid and ice cloud microphysics in the CSU General Circulation Model. Part II: Impact on cloudiness, the Earth's radiation budget, and the general circulation of the atmosphere. J. Climate, 9, 530-560.
[3] Ou, S. C., and K. N. Liou, 1995: Ice microphysics and climate temperature feedback. Atmos. Res., 35, 127. 138.

[4] Platt, C. M. R., 1989: The role of cloud microphysics in high-cloud feedback effects on climate change. Nature 341, 428 429 .

[5] Heymsfield, A. J., 1977: Precipitation development in stratiform ice clouds: A microphysical and dynamical study. J. Atmos. Sci. 34, 367-381.

[6] Heymsfield, A. J., and Platt, C. M. R. 1984: A parameterization of the particlc size spectrum of ice clouds in terms of the ambient temperature and the ice water content. J. Atmos. Sci. 41, 846-855.

[7] McFarquhar, G. M., and A. J. Heymsfield, 1996: Microphysical characteristics of three cirrus anvils sampled during the Central Equatorial Pacific Experiment. J. Atmos. Sci., 53, 2401-2423.

[8] Platt, C. M. R., J. C. Scott, and A. C. Dilley, 1987 Remote sounding of high clouds. VI, Optical properties of midlatitude and tropical cirrus, $J$. Atmos. Sci., 44, 729-747.

[9] Atlas, D., S. Y. Matrosov, A. J. Heymsfield, M. D. Chou, and D. B. Wolff, 1995: Radar and radiation properties of ice clouds. J. Appl. Meteor., 34, 23292345.

[10] Matrosov, S.Y., D. Atlas, A.J. Heymsfield, and R.A. Kropfli, 1995: Variations of cirrus cloud particle sizes with temperture: Results of remote sensing and direct measurements. Preprints, Cloud Physics Conf., Dallas, TX, Amer. Meteor. Soc., 55-58.

[11] Brown, P. R. A., A. J. Illingworth, A. J. Heymsfield, G. M. McFarquhar, K. A. Browning, and M. Gosset, 1995: The role of space borne millimeter-wave radar in global monitoring of ice cloud. J. Appl. Meteor., 34, 2346-2366

[12] Han, Q.Y., W.B. Rossow, J. Chou, and R.M. Welch, 1997: A near-global survey of ice cloud properties using ISCCP, Part I: Methodology. [Submitted to J. Climate, Accepted]

[13] Mishchenko, M.I., W.B. Rossow, A. Macke, and A.A. Lacis, 1996: Sensitivity of cirnus cloud albedo, bidirectional reflectance and optical thickness retrieval accuracy to ice particle shape. J. Geophys. Res., 101, 16973-16985.

[14] Prabhakara, C., R.S. Fraser, G. Dalu, M.L.C. Wu and R.J. Curran, 1988: Thin cirrus clouds: Seasonal distribution over oceans deduced from Nimbus 4 IRIS. J. Appl. Meteor., 27. 379-399. 
